\title{
A REVISÃO DE ARTIGOS CIENTÍFICOS \\ NA ÁREA DE ADMINISTRAÇÃO: \\ CONSIDERAÇÕES COM BASE NA \\ HERMENÊUTICA FILOSÓFICA
}

\author{
THE REVIEW OF SCIENTIFIC PAPERS IN MANAGEMENT: \\ THOUGHTS FROM \\ THE PHILOSOPHICAL HERMENEUTICS PERSPECTIVE
}

Recebido em: 02/06/2015 • Aprovado em: 10/08/2015

Avaliado pelo sistema double blind review

Editora Científica: Manolita Correia Lima

DOI: $10.13058 /$ raep.2015.v16n 4.382

\author{
DOUGLAS CABRAL DANTAS douglas.dantas@yahoo.com.br \\ ROBERTO PATRUS \\ PONTIFÍCIA UNIVERSIDADE CATÓLICA DE MINAS GERAIS
}

\section{RESUMO}

A avaliação de artigos científicos, embora esteja no coração de toda a ciência, é um processo que está sujeito a imprecisões. O objetivo deste trabalho é contribuir para o aprimoramento dessa tarefa, por meio do referencial teórico da Hermenêutica Filosófica. A pesquisa analisou duas revistas da área de Administração, uma brasileira e outra colombiana, tendo como objetos de análise (i) os formulários de avaliação de artigos das revistas e (ii) pareceres de avaliadores acerca de uma amostra de artigos. A técnica de coleta de dados utilizada foi a pesquisa documental e como procedimento metodológico, a Análise de Conteúdo. Os resultados da pesquisa revelaram duas revistas com concepções e políticas de avaliação distintas. Dentre as conclusões, destacam-se (i) que a maior contribuição do revisor se dá no âmbito das recomendações que ele faz ao artigo, (ii) que a possibilidade de total convergência entre revisores de um mesmo artigo só é possível no tocante a aspectos formais do texto, (iii) que a identificação da relevância do artigo depende da formação em sentido amplo do revisor, e (iv) que programas de treinamento de revisores garantem apenas convergência no que diz respeito à avaliação formal do artigo. Acredita-se que com a adoção de uma Postura Hermenêutica, procedimento identificado e assumido durante a pesquisa, a tarefa do avaliador pode ganhar em competência.

Palavras-chave: Revisão por Pares; Hermenêutica Filosófica; Gadamer; Postura Hermenêutica.

\footnotetext{
ABSTRACT

Although the evaluation of scientific papers is at the heart of all science, it is a process subject to inaccuracies. The objective of this work is to contribute to the improvement of this task through the theoretical framework of Philosophical Hermeneutics. The research examined two management journals, one Brazilian and the other Colombian, while the objects of the analysis were: (i) the paper assessment forms used by the journals, and (ii) the reviewers' opinions on a sample of papers. The data collection technique used was documentary research and content analysis was employed as the methodological procedure. The findings revealed two journals with different assessment concepts and policies, of which we highlight (i) that a reviewer's greatest contribution lies in his or her suggested recommendations, (ii) that there is no possibility of convergence among reviewers for any specific paper, (iii) the identification of a paper's importance depends on the reviewer's education, in a broad sense, and (iv) that reviewer training programs only ensure convergence with regard to a paper's formal assessment. The conclusion reached is that adopting the Hermeneutics approach, as employed in this study, may lead to increased competence in reviewers.

Keywords: peer review; Philosophical Hermeneutics; Gadamer; Hermeneutics approach.
} 


\section{INTRODUÇÃO}

Desde a sua regulamentação em I95I, a pós-graduação no Brasil associou a iniciativa do Estado, o progresso da ciência e a busca de referências internacionais de conhecimento. Ela tem-se feito acompanhar de um quadro legal que comporta um sistema de autorização, credenciamento conduzido por pares, financiamento, e bolsas para mestrado e doutorado. E, desde logo, fez e continua fazendo parte dessa sistemática um processo rigoroso e detalhado de avaliação de cursos e programas (ALCADIPANI, 20II; CRUZ, 2009; CURY, 2005; MACCARI, 2008; NOSELLA, 20I0).

A avaliação de programas de pós-graduação pela Coordenação de Aperfeiçoamento de Pessoal de Nível Superior (CAPES) está centrada na formação do pesquisador, enquanto a formação do professor se tornou uma "dimensão esquecida" (PATrus; LIMA, 20I4). Esta ênfase na formação do pesquisador, por sua vez, é acompanhada da valorização da publicação científica, o que favorece o produtivismo acadêmico. O fenômeno do produtivismo teve sua origem nos anos 1950, nos EUA, e tornou-se mundialmente conhecido pela expressão public or perish, significando que os professores/pesquisadores universitários que não publicassem de acordo com os parâmetros postos como ideais pelos órgãos financiadores, pela burocracia universitária ou pelo mercado, teriam sua carreira comprometida (FONSECA, 200I; NASCIMENTO, 20IO; SGUISSARDI, 20IO).

No Brasil, esse fenômeno tem sido alvo de críticas que o associam direta ou indiretamente à implantação do atual modelo de avaliação da pós-graduação stricto sensu pela CAPES, agência estatal de financiamento, regulação e controle, nos anos 1996/1997, a partir de quando se intensificaram os critérios quantitativos de produção acadêmica como parâmetros para a classificação dos cursos de mestrado e doutorado em todas as áreas (SGUISSARDI, 20Io). Essa mudança de paradigma se deu quando a CAPES, para corresponder ao padrão internacional de pós-graduação, tendo em vista as exigências de crescimento econômico do País, passou a privilegiar a pesquisa (ênfase epistemológica: fazer ciência) e não mais a docência (ênfase pedagógica: ensinar ciência). Como decorrência desse movimento, 
acentuou-se a pressão pela produção científica, que se tornou um critério decisivo - de natureza formal, quantitativa - de avaliação de programas de pós-graduação e da atividade do pesquisador (PATRUs; LIMA, 20I4).

O que tem se verificado nos últimos anos, particularmente na área de Administração, é o crescimento exponencial da produção de artigos científicos, apresentados em eventos e depois publicados, fato este acompanhado não de agora de um questionamento quanto a sua relevância para a academia e sociedade (BERTERO; CALDAS; WOOD JR., I999; BRITO, 2009; DINIZ, 2OI2A, 20I2B, 20I2C; KIRSCHBAUM; MASCARENHAS, 2009; ROESCH, 2003). A investigação sobre o processo de avaliação de artigos científicos põe em destaque a modalidade de avaliação por pares, a qual assegura a legitimidade do sistema de avaliação da pós-graduação pela CAPES, na medida em que esse julgamento é indicado por sociedades científicas (MATTOS, 2008). A avaliação por pares se constitui, para Fitzpatrick (20II), no centro de tudo o que fazemos: escrita, submissão para aprovação de projetos, busca de emprego e até obtenção de promoções.

A realidade que se apresenta é a seguinte: a publicação acadêmica é uma prioridade no âmbito da avaliação de programas de pós-graduação no Brasil; a avaliação por pares é central para a publicação científica; a avaliação por pares depende da compreensão e interpretação dos artigos pelos revisores, os quais estão sujeitos a idiossincrasias e preconceitos; e, diante da possibilidade de avaliações indevidas, o consequente comprometimento da transparência e justiça do processo de avaliação dos programas de pósgraduação. A avaliação por pares, cujo processo exige que os artigos tenham base conceitual e métodos científicos, não nos dá garantias de que ela própria adote esses critérios. Avaliar é preciso (necessário), mas avaliar não é "preciso" (exato) (PATRUs; DANTAS; SHIGAKI, 20I3).

Diante deste cenário, recorreu-se à ciência hermenêutica como referencial teórico para pensar e subsidiar a tarefa de avaliação do texto científico. Para a finalidade deste estudo, adotou-se a obra de Hans-Georg Gadamer por se considerar que a sua hermenêutica pode fornecer pressupostos e critérios importantes para a compreensão e interpretação de um texto, particularmente do texto científico. A hermenêutica filosófica, na perspectiva gadameriana, possui uma tarefa crítica e não se restringe a uma teoria ou 
metodologia de compreensão e interpretação da fala e do texto, cabendolhe determinar o verdadeiro sentido das ciências humanas e a verdadeira amplitude e significado da linguagem humana (DISCHINGER, 2003).

ESTE TRABALHO ${ }^{\mathrm{I}}$ TEM POR OBJETIVO GERAL INVESTIGAR A CONTRIBUIÇÃO DA Hermenêutica de Gadamer para a avaliação de artigos científicos na área de Administração; e, por específicos, (i) analisar a contribuição de revistas acadêmicas da área de Administração para a Postura Hermenêutica do revisor, baseada na análise da concepção e política de avaliação de artigos por elas propostos; e (ii) analisar de que modo os critérios utilizados por revisores de artigos científicos de revistas acadêmicas da área de Administração refletem o encontro entre a tradição do revisor e o texto, ou seja, a fusão de horizontes.

1 Um dos autores deste trabalho é beneficiário de auxílio financeiro da Coordenação de Aperfeiçoamento de Pessoal de Nível Superior (CAPES), a qual agradecemos pelo apoio e viabilização do Projeto Colciências, que intercambia pesquisadores do Brasil e da Colômbia. 


\section{A REVISÃO POR PARES}

A avaliação por pares de artigos científicos é um processo que está no coração de toda a ciência (FITZPATRICK, 20II) e que, por sua importância, poderia ser comparado com a democracia: “... um sistema cheio de problemas, mas o menos pior que temos." (SMITH, 2006, P.I78). Trata-se da avaliação crítica de manuscritos submetidos a revistas, por especialistas que não fazem parte da equipe editorial, podendo ser vista como uma extensão importante do processo científico (FREITAS, I998; HAMES, 20I2; ICMJE, 20I3), o que faz com que essa produção seja também considerada de autoridade no assunto (sTUMPF, 2008; FITZPATRICK, 20II). Segundo o International Committee of Medical Journal Editors (ICMJE, 20I3), embora seu valor real tenha sido pouco estudado e ser amplamente debatido, a avaliação por pares ajuda os editores a decidirem quais artigos são adequados para suas revistas, e ajuda autores e editores a melhorarem a qualidade dos seus trabalhos. O número e os tipos de artigos enviados para revisão, o número de revisores, os procedimentos de revisão, bem como a utilização de opiniões dos revisores podem variar (ICMJE, 20I3).

Uma pesquisa recente com revisores de artigos brasileiros, com o objetivo de analisar o processo de avaliação por pares em um contexto de produtivismo acadêmico (SHIGAKI, 20I4), identificou que as avaliações na área de Administração seguem, via de regra, o padrão exigido pela própria revista, previsto no formulário de avaliação disponível para o revisor junto com o artigo a ser avaliado. No entanto, apesar de seguirem esses critérios, os revisores entrevistados consideravam que alguns deles eram mais importantes do que outros e, por isso, lhes davam maior peso. No tocante aos critérios pessoais do revisor - suas experiências e preferências algumas subjetivizações foram apuradas: a identificação com a natureza do artigo, se teórico ou empírico; o mérito para uma publicação; se o título é provocativo; se o revisor tem algo novo a aprender com o artigo; e se o autor mostra preguiça ou disposição na construção do seu texto (sHIGAKI, 20I4).

O debate sobre a relevância dessa produção passa não só pela análise do padrão de excelência nacional frente o internacional, mas também, segundo Kirschbaum e Mascarenhas (2009), pelo debate acerca dos modelos de 
avaliação e publicação de artigos, pela discussão sobre o grau de autonomia dos revisores no processo, e pelos desafios organizacionais que envolvem os editores e o conselho editorial na construção de artigos de alta relevância e impacto. Uma vez que se constatam fragilidades de natureza epistemológica, sobretudo contradições teóricas em boa parte dessas publicações (por exemplo, entre epistemologia e metodologia), além de artigos "maquiados" e "requentados", depreende-se que também o editor e o revisor - dois atores centrais no processo de avaliação de artigos científicos - estão despreparados epistemologicamente (BERTERO; CALDAS; WOOD JR., I999; CALDAS, 2005; KIRSCHBAUM; MASCARENHAS, 2009; LeITE et al., 20II; MACHADO, 2007; MATTOS, 2008, 20I2; RODRIGUES, 200I; ROESCH, 2003).

Na apreciação de Mattos (2008), a relevância da produção científica está comprometida pela valoração da sua qualidade formal em detrimento da qualidade do conteúdo e da sua destinação social, requisito para autopromoção pessoal e legitimação institucional. A academia não deveria ter como finalidade principal a publicação de seus resultados de pesquisa, mas ter claro que os produtos da atividade investigativa são meios para o desenvolvimento humano, social, econômico e financeiro, não somente das empresas, mas da sociedade. Portanto, a publicação como contribuição ao crescimento e desenvolvimento social ajuda a problematizar o fenômeno do produtivismo acadêmico se for levado em conta o critério da destinação SOCial (JARAMILLO; HINCAPIÉ; PATRUS, 20I3). 


\section{A HERMENÊUTICA DE GADAMER}

A Hermenêutica Filosófica de Hans-Georg Gadamer (2005 apud BRESOLIN, 2008, p.73-4) toma o homem como ele é - finito e histórico. Sua preocupação não é com a intenção do autor, mas com a fusão de horizontes entre o leitor-intérprete e o texto, quando o intérprete ajustou e continua a ajustar sua pré-compreensão no aparecimento da obra enquanto tal. $\mathrm{O}$ encontro com a coisa mesma é a prova de fogo para os preconceitos, uma vez que são distinguidos os verdadeiros dos falsos. É o encontro com a obra que proporá uma revisão da pré-compreensão. Portanto, é uma relação dialógica, onde o intérprete põe a escutar a coisa mesma, a fim de confirmar ou não seus preconceitos. É nesta relação de diálogo, entre Eu-Tu, que se dará a filtragem da pré-compreensão. Disso resulta sempre uma revisão do projeto. (GADAMER, 2005 apud BRESOLIN, 2008, p.73-4). Este é o novo sentido da verdade hermenêutica: não subjetiva, mas intersubjetiva (sILVA, I992, p.I4I).

Os preconceitos são tratados no pensamento gadameriano como fundamentais para a compreensão de uma obra, pois eles formam a pré-compreensão do seu sentido. Logo, os preconceitos são condições inevitáveis de um ser-no-mundo. Ou ainda, ser homem é estar submetido às contingências determinantes de sua vivência temporal. Não há necessidade da negação dos preconceitos que, desde sempre, estão presentes no homem. Eles são a própria condição de possibilidade do compreender. Estes preconceitos são frutos da tradição na qual estamos inseridos, são o horizonte com base no qual compreendemos. Por fim, os preconceitos são esta carga histórica que sempre caminha conosco determinando, juntamente com o encontro com a coisa mesma, o como compreendemos (GADAMER, 2005 apud BRESOLIN, 2008, p.72-3).

Na hermenêutica de Gadamer (2005 apud воNFIM, 20I0) a ideia de um conhecimento universalmente válido é insustentável e uma verdade absoluta não pode ser generalizada com base em uma experiência particular e histórica. Daí a expressão "hermenêutica da finitude", alusiva ao reconhecimento, pelo leitor-intérprete, do próprio limite imposto por seus preconceitos à compreensão e interpretação de qualquer realidade, inclusive do texto. Isto 
quer dizer que aquele que pretende compreender não pode entregar-se de antemão ao arbítrio de suas próprias opiniões prévias, mas deve estar disposto a deixar que estas lhe digam algo. Para Gadamer tem de haver, antes de tudo, a apropriação de opiniões prévias e preconceitos pessoais, pois é fundamental dar-se conta dos próprios pressupostos, a fim de que o próprio texto possa se apresentar em sua alteridade, confrontando-se, assim, a verdade do texto com as opiniões prévias pessoais do leitor-intérprete (GADAMER, 2005 apud BONFIM, 20I0).

Contra o ideal de uma autoconsciência completa, próprio da Ilustração, Gadamer (2003 apud HERRERo, 2009) propõe a reabilitação da autoridade da tradição, transmissora de um saber de fundo, procedente da abertura linguística do mundo e, por isso, constitutivo de tudo o que possa aparecer nele. Além disso, ele procura restituir a autoridade normativa vinculante da tradição para os indivíduos que nela se encontram ou para os futuros intérpretes. Daí Gadamer considerar a tradição como algo não objetivável, como um Tu, com o qual se tenha que dialogar. Trata-se de mostrar que aquele, com quem queremos chegar a um acordo (também o texto científico a ser avaliado), há de ser levado a sério em sua pretensão de verdade para o que diz. Com isso, Gadamer recupera, na sua concepção de linguagem, a dialética entre uma intersubjetividade pré-estabelecida (garantida pela abertura do mundo compartilhada) e uma intersubjetividade a conseguir pelo acordo mútuo. Os dois polos da dialética, no entanto, não são do mesmo nível: o entendimento não pode acontecer entre os participantes com base em um contexto zero, mas numa constituição de sentido previamente compartilhada. Sendo assim, a constituição de sentido ou abertura do mundo é tanto a condição de possibilidade do entendimento como também a instância última que garante a validade do entendimento (GADAMER, 2003 apUd HERRERO, 2009, p.I82-I83).

Participar nessa constituição de sentido ou a pertença à tradição é uma condição sine qua non de todo compreender. Gadamer não mostra apenas a dependência fática de todo compreender com respeito aos preconceitos do intérprete, mas ele pretende ainda que essa conexão com a tradição seja vista como uma "fonte de verdade". É assim que Gadamer reabilita 
a autoridade da tradição (GADAMER, 2003 apud HERRERo, 2009, p.I73.I86I87). Então, interpretar não é 'impor' um sentido, mas 'encontrar' um sentido. Ora, o que caracteriza o conceito de texto para Gadamer é que este somente se apresenta à compreensão no contexto da interpretação e aparece como uma realidade dada à luz da interpretação. Analogamente, o intérprete de um texto pergunta pelo que há propriamente nele, no texto. Essa pergunta poderá ser respondida com pressuposições e preconceitos, uma vez que aquele que pergunta busca uma confirmação direta de suas próprias suposições. O texto aparece, assim, como um ponto de referência fixo frente à problematicidade, arbitrariedade ou no mínimo a pluralidade de possibilidades interpretativas para o mesmo (GADAMER, I994b, p.392).

Particularmente no caso da comunicação científica, esta pressupõe determinadas condições de entendimento, o que depende do destinatário; ou seja, a comunicação científica, embora seja publicada, não é válida para todos, mas pretende ser compreensível para aquele que está familiarizado com a situação da investigação e sua linguagem. Deste modo, a escrita abre no próprio texto um horizonte de interpretação e compreensão que o leitor mesmo deve preencher de conteúdo (GADAMER, I994b, p.396-398).

Neste sentido, cada compreensão, vista como auto-compreensão, é motivada e inquietada por perguntas que determinam, de antemão, as "trilhas visuais da compreensão" (GADAMER, I974 apud GRONDIN, I999). Um texto só se torna "falante" graças às perguntas que nós, enquanto leitoresintérpretes, mas também revisores, lhe dirigimos atualmente. Sendo assim, não existe nenhuma interpretação, nenhuma compreensão, que não responda a determinadas interrogações que anseiam por orientação. Para Gadamer (I974 apud GRONDIN, I999, p.I94-95), não devemos empenhar-nos pela exclusão das nossas expectativas de sentido, e sim por realçá-las, para que os textos que procuramos entender possam responder-lhes tanto mais nitidamente.

Como, então, compreender e interpretar artigos científicos e gerar um parecer que seja condizente com a natureza mesma do texto, em diálogo com a tradição acadêmica e com o horizonte epistemológico do intérprete-revisor? Como, em última instância, contribuir para a formação de pós-graduandos, 
potenciais revisores de artigos científicos? Com base no arcabouço teórico de Gadamer, forjou-se o conceito de Postura Hermenêutica para a nossa investigação e, quiçá, uma contribuição para a Área. O conceito de Postura Hermenêutica pode ser definido como uma pré-disposição interior para agir, respeitando as determinações provenientes do próprio objeto considerado e suas derivações epistêmicas, o que supõe posicionar-se de forma crítica, reflexiva e aberta a compreender a complexidade diante da qual o leitorintérprete-revisor se coloca.

A Postura Hermenêutica também pode ser entendida como uma competência do revisor, postura que reúne maturidade humana e honestidade intelectual para lidar com os próprios e inevitáveis preconceitos, de modo que não se sobreponham à realidade mesma do texto científico, mas que se coloquem a serviço dela. Em outras palavras, a Postura Hermenêutica condensa duas das mais importantes categorias de interpretação propostas por Gadamer: a fusão de horizontes (entre texto e intérprete) e a autoridade da tradição (no nosso caso, a tradição acadêmica da área de especialidade do revisor).

O conceito de Postura Hermenêutica também está em sintonia com o Manual da ANPAD (20I0), que preconiza que o principal objetivo do revisor é o aperfeiçoamento do artigo, tarefa esta que requer tempo suficiente, critério e discernimento, autocrítica quanto a uma eventual divergência de paradigma epistemológico, autocrítica quanto a sua qualificação na apreciação de determinada área ou matéria, cumprimento do prazo estabelecido pelo periódico para a devolução do artigo avaliado ou a negociação de sua alteração, apontar as limitações corrigíveis do artigo e recomendar alterações para a sua superação, inclusive com sugestões de referências relevantes; e, no caso de falhas incorrigíveis, justificar com objetividade e clareza o seu parecer. Além disso, o Manual da ANPAD (20I0) recomenda que o revisor proceda a uma primeira leitura em profundidade do artigo para ter dele uma percepção geral, não se preocupando nesse momento com aspectos específicos, para, num segundo momento, alguns dias depois, retomar o texto, agora sim pormenorizadamente, e elaborar o seu parecer. Segundo Gadamer (1994b), a fusão de horizontes só é possível após este distanciamento temporal. 


\section{MÉTODO}

Como investigação inserida no campo das Ciências Sociais, optou-se pela pesquisa qualitativa (GODOY, I995), tendo como procedimento básico a Análise de Conteúdo (AC). Dentre os vários tipos de AC, adotou-se a Direta (ACD), aquela que se ocupa do sentido literal do que está sendo estudado. Neste caso, não há nenhuma tentativa de revelar um possível significado latente das unidades analisadas, mas ficar simplesmente e diretamente no nível do significado manifesto (AKTOUF, 1990).

Foram selecionadas como objeto de análise duas revistas patrocinadas por instituições que agregam cursos de pós-graduação em Administração, uma nacional e outra internacional. Além disso, foram analisados os pareceres de artigos submetidos às duas revistas, num mesmo período de tempo. No entanto, para resguardarmos o sigilo em torno da autoria e avaliação dos artigos, conforme acordo firmado com a editoria das duas revistas, optouse por não divulgar a íntegra dos pareceres e resumos, como também comentários e recomendações que "denunciariam" a identidade do artigo e seu autor. Nesse intuito também, em nenhum momento da coleta e análise de dados recorreu-se aos artigos e autores que "originaram" os pareceres dos revisores.

A Revista brasileira pesquisada possui reconhecida expertise dentre as revistas científicas na área de Administração. Trata-se da Revista de Administração de Empresas (RAE), publicada pela Escola de Administração de Empresas de São Paulo (eAESP), da Fundação Getulio Vargas (FGV), a primeira revista científica brasileira na área, lançada em I96I. A Revista possui alto fator de impacto pelo número de suas citações e está em renomados indexadores e diretórios, tendo classificação A2 pela CAPES à época da pesquisa. De periodicidade bimestral, a RAE tem se consolidado como uma publicação generalista de referência nos meios acadêmicocientífico e empresarial.

A Revista internacional, por sua vez, é colombiana - a Semestre Económico - publicação semestral da Faculdade de Ciências Econômicas e Administrativas da Universidade de Medellín (UdeM), criada em I983 e à 
época da pesquisa classificada também como A2, de acordo com o Índice Bibliográfico Nacional de Publicaciones Seriadas Científicas y Tecnológicas Colombianas de colciencias (Publindex). Tratava-se de um espaço de divulgação e investigação regional e nacional de reflexões acadêmicas em diferentes campos das ciências econômicas, sociais e administrativas.

A pesquisa foi dividida em três etapas: as duas primeiras, a pesquisa documental e o trabalho de campo, foram demarcadas pelo uso da técnica de coleta de dados; e a terceira consistiu na Análise de Conteúdo Direta (AKTOUF, 1990) dos critérios de avaliação das Revistas e de pareceres de seus revisores. Tanto a pesquisa documental quanto o trabalho de campo tiveram como objetivo confirmar os aportes que o referencial teórico nos trouxe, em particular a hermenêutica gadameriana. Os editores autorizaram revelar a identidade das Revistas no estudo, reiterando a importância de se manter sigilo sobre a identidade de artigos e autores, e editores e revisores envolvidos.

\section{A PESQUISA DOCUMENTAL}

O primeiro procedimento de manipulação dos dados foi identificar nos sites das Revistas e outros arquivos eletrônicos disponibilizados pelas equipes editoriais os critérios de avaliação de artigos científicos que são de domínio público (RAE) e aqueles que são restritos aos revisores por meio de instrumentos específicos, geralmente formulários (RAE e Semestre Económico). Já a relação dos pareceres das duas Revistas a serem analisados foi feita com o auxílio das respectivas equipes editoriais, que disponibilizaram seus arquivos eletrônicos por ocasião dos trabalhos de campo.

Isto resultou na construção de quadros-resumo com apresentação do check list ou critérios de avaliação das Revistas; sua classificação em subcategorias, com base em uma primeira generalização; e para cada conjunto de subcategorias de mesma natureza, uma categoria também correspondente. Tendo em vista o estabelecimento de um paralelo entre as duas Revistas, identificaram-se Macrocategorias de avaliação de artigos recomendados por ambos os veículos, por meio dos instrumentos de acesso restrito por autores e revisores; como também Macrocategorias adotadas pelos revisores 
por meio de seus pareceres. Procurou-se, sempre que possível, estabelecer um diálogo entre esses procedimentos e o construto Postura Hermenêutica, contribuição maior desta pesquisa.

Os quadros elaborados para cada um desses comparativos distinguiram Elementos Generalizáveis de Específicos, procurando ressaltar a frequência (ou grau de convergência) das Categorias utilizadas. A relevância da frequência está justamente em nos possibilitar verificar se a ênfase dos critérios recomendados pela Revista e utilizados pelos revisores recai sobre critérios que estão resguardados de eventuais idiossincrasias, como no caso de critérios analíticos; ou favorece a fusão de horizontes e o recurso à tradição acadêmica, quando se supõe que o revisor está mais propenso à exposição da sua subjetividade e o consenso entre revisores torna-se mais difícil, como no caso de critérios globais.

\section{O TRABALHO DE CAMPO}

Os dados da pesquisa documental precisaram ser complementados e esclarecidos com o recurso às fontes primárias, ou seja, às equipes editoriais, tendo em vista captar a sua experiência e percepção do processo de avaliação de artigos científicos.

A experiência de imersão junto à RAE aconteceu em maio de 2013. Os contatos e atividades que se estenderam por uma semana consistiram em acompanhar cada uma das etapas do processo de avaliação, desde a triagem de formato, passando pelo Desk Review (primeiro filtro) a cargo do Diretor e Editor; e a experiência da editoria científica (segundo filtro) e dos revisores ad hoc (terceiro filtro). O critério para a escolha de pareceres a serem analisados foi de trabalhar com aqueles referentes a artigos que percorreram todas as etapas do processo de avaliação, até a data do trabalho de campo, independentemente de terem sido publicados ou recusados. Dentre mais de uma centena de trabalhos submetidos no $\mathrm{I}^{\mathrm{o}}$. semestre de 20I2, foram identificados 26 pareceres correspondentes a I2 artigos.

A experiência de compartilhamento junto à Semestre Económico, da Universidade de Medellín, realizou-se em junho de 2013. Tratou-se de uma missão de estudos prevista como uma etapa de desenvolvimento de dois 
Programas da CAPEs dos quais participa o Programa de Pós-graduação em Administração da PUc Minas: o Pró-Administração, responsável por um projeto sobre a formação do professor de Administração; e o Colciências, que pesquisa a educação e o ensino na formação dos administradores e na avaliação de trabalhos acadêmicos, numa parceria com investigadores da universidade de Medellín, Colômbia. Quanto aos artigos que percorreram todas as etapas do processo de avaliação, foram identificados 15 , a fim de serem analisados seus respectivos pareceres. 


\section{ANÁLISE DOS DADOS}

Para a análise dos critérios de avaliação das Revistas e dos pareceres dos revisores optou-se por um processo de categorização (BARDIN, 2003) alinhado com a definição de Postura Hermenêutica, que parte dos dados e procura interpretá-los pela fusão dos horizontes entre o texto (pesquisa documental, sobretudo os pareceres) e o leitor (revisores e os autores deste trabalho).

\section{O PROCESSO DE AVALIAÇÃO DE ARTIGOS CIENTÍFICOS DA RAE}

Quanto à submissão de artigos, a RAE os avalia pelo sistema de avaliação duplo-cega ou blind review. Os trabalhos são encaminhados à redação pela internet por meio de um sistema de gestão de publicações, cujo acesso é feito por um link denominado Espaço de Autor e Avaliador. O próprio sistema fornece um código para cada artigo submetido, para manter seu(s) autor(es) no anonimato; caso o artigo seja resubmetido, receberá um novo código. Os autores só podem submeter um artigo por vez. Caso o trabalho seja rejeitado em uma das etapas do processo é possível o autor submeter o mesmo artigo aprimorado ou um novo artigo. Os artigos devem ser inéditos e não devem ter sido submetidos a outro periódico.

Pelo endereço eletrônico do periódico é possível identificar na aba "Avaliação" um conjunto de recomendações reunidas sob o título "Orientação para pareceristas", as quais, por sua vez, estão subdivididas em quatro subtítulos: (I) Foco da avaliação; (II) Redação e Estilo; (III) Conteúdo dos Pareceres; e (Iv) Recusa de Trabalhos. Desmembraram-se cada um desses subtítulos por suas unidades (ou afirmações) autônomas, associaram-se cada uma delas a uma subcategoria (primeiro grau de generalização) e, estas, a categorias de maior generalização (porque mutuamente excludentes).

Essas categorias correspondem a elementos constitutivos do artigo, e foram agrupadas sob o título de "Elementos generalizáveis". As categorias estão acompanhadas da frequência com que foram recomendadas pela Revista, sendo possível identificar aquelas mais enfatizadas dentre os critérios de avaliação de domínio público e sua maior ou menor contribuição para a Postura Hermenêutica do revisor. Também foram identificadas 
recomendações menos objetivas que permitem maior liberdade de opinião por parte do revisor e que foram classificadas de "Elementos específicos".

Observando mais atentamente a natureza das categorias foi possível distinguir aquelas que correspondem a partes componentes (ou constitutivas) do artigo, e que foram denominadas de "Critérios Analíticos"; e aquelas que perpassam a totalidade do artigo, como elementos transversais, denominadas de "Critérios Globais". A esta subdivisão foi atribuída uma nova categorização, a de Macrocategorias.

Além dos critérios de avaliação de artigos tornados públicos, existe outro conjunto de recomendações mais pontuais que complementam e aprofundam aqueles. Trata-se de um instrumento de acesso restrito, um check list a que os revisores têm acesso por meio de formulário específico e do qual os autores também tomam conhecimento. Também foi possível categorizar os comentários e recomendações (Elementos Específicos) utilizados pelos revisores dos artigos avaliados.

O consolidado desses critérios possibilitou comparar ainda as categorias utilizadas pelos revisores dos artigos com os pareceres entre si, de modo que obteve-se uma visão geral das convergências de critérios de avaliação. Pôdese constatar que mesmo um processo de avaliação criterioso como o da RAE não tem como evitar que seus revisores se pronunciem com olhares distintos sobre categorias de um mesmo artigo. Essas discrepâncias "sobram" para o editor científico mediar, já que os revisores só são solicitados uma única vez e a continuidade do processo, caso o artigo venha a ser aperfeiçoado, caberá a ele como "padrinho" do trabalho submetido.

\section{O PROCESSO DE AVALIAÇÃO DE ARTIGOS DA REVISTA SEMESTRE ECONÓMICO}

A revista colombiana Semestre Económico, da Universidade de Medellín, detém um processo de avaliação de artigos científicos que prevê o envolvimento direto e decisivo da equipe editorial e a contribuição dos revisores externos. A Revista era composta, à época do trabalho de campo, por uma Equipe Editorial (Editor e dois Assistentes), um Comitê Editorial (oito membros, dentre os quais o Editor) e um Comitê Científico (quatro membros). 
O endereço eletrônico da revista Semestre Económico não antecipa para o público em geral critérios de avaliação dos artigos científicos submetidos à publicação, mas apenas por meio de instrumento de acesso restrito do autor e revisor.

Quanto aos pareceres foram analisados $\mathrm{I}_{5}$, referentes aos I5 artigos que percorreram todas as etapas do processo editorial, já que apenas um revisor externo é convidado para avaliar cada artigo. Chegou-se, assim, à síntese dos elementos específicos recomendados, como também às categorias generalizáveis utilizadas pelos revisores na avaliação dos artigos.

\section{CONTRIBUIÇÃO DOS CRITÉRIOS DE AVALIAÇÃO DAS REVISTAS RAE E SEMESTRE ECONÓMICO PARA A POSTURA HERMENÊUTICA}

Na pesquisa junto às Revistas foi possível reconhecer que quanto mais claros e abrangentes os critérios de avaliação recomendados, como é o caso da RAE, onde verificamos convergência entre as preocupações da Revista e a expertise/tradição de seus revisores, maiores as possibilidades de que a tarefa de avaliação de artigos seja bem sucedida, uma vez que essa política favorece a Postura Hermenêutica. Isto sugere a adoção de uma política transparente, aberta a críticas e contribuições.

A RAE antecipa para o público externo a maior parte dos critérios de avaliação que recomenda aos seus revisores, o que pode favorecer maior diálogo com a comunidade científica e público em geral. A RAE também fornece mais critérios de avaliação para o revisor, sobretudo analíticos, com destaque para os Metodológicos e de Análise de Dados. Já a Semestre Econômico concentra a maior parte de suas recomendações nos critérios globais, com predominância para a Qualidade do Texto, ou seja, um critério formal.

Uma convergência perceptível diz respeito aos critérios metodológicos, igualmente valorizados por ambas as Revistas, o que mostra o quanto este componente é central na construção de um artigo e deve merecer atenção particular por parte do revisor.

No tocante aos elementos específicos, constatou-se uma maior diversidade de critérios propostos pela RAE do que a Semestre Económico, o que sugere 
um processo de avaliação de artigos mais criterioso por parte da primeira, o que, em tese, diminui a margem de subjetivismo a que está sujeito o revisor, uma vez que ele se encontra mais "supervisionado" pela Revista. Neste caso, a Postura Hermenêutica, de atenção ao texto do artigo e interpretação com base em uma fusão de horizontes e tradição acadêmica, pode ser beneficiada por esse suporte epistemológico/metodológico fornecido pela Revista.

Constatou-se o comprometimento do rigor epistemológico e o diálogo da revista Semestre Económico com autores e revisores, uma vez que ela se encontrava refém de fatores como escassez de recursos, cumprimento de prazos e disponibilidade de revisores, aumentando o poder do editor.

Os editores das duas revistas tinham a última palavra quanto à publicação do artigo, assumindo o papel de gatekeeper. Ora, também eles, conhecedores da autoria do artigo, estão sujeitos a preconceitos que podem comprometer a transparência e justiça do processo. Mesmo a RAE, que detém um criterioso processo de avaliação de artigos, está sujeita a um viés dessa natureza.

Lançar mão de apenas um revisor para a avaliação de artigos, como na revista colombiana, empobrece a Postura Hermenêutica, já que não existe o benefício da dúvida no processo de avaliação. A Postura Hermenêutica, que coloca o preconceito em suspenso, é fortalecida pelo exercício da intersubjetividade. Como o intérprete pode não conseguir distinguir por si mesmo os preconceitos produtivos daqueles que levam a mal entendidos, é recomendável que ele faça parte de um "cérebro coletivo", uma comunidade de iguais, para minimizar tal parcialidade, privilegiando a decisão colegiada sobre a decisão individual, a intersubjetividade sobre pretensa objetividade ou subjetividade ideais. O consenso, diferentemente da unanimidade, não acontece entre os participantes com base em um contexto zero, mas numa constituição de sentido compartilhado (PATRUs; LIMA, 20I4).

Com base na categoria de autoridade da tradição do leitor-intérprete, não há possibilidade de total convergência entre revisores de um mesmo artigo, pois seus preconceitos são diferentes e a fusão de horizontes tende a ser também distinta. Isto foi ilustrado quando da verificação da convergência das categorias de avaliação utilizadas pelos revisores da RAE. O simples consenso entre revisores acerca de um artigo não deve ser critério absoluto da sua 
relevância. Pareceres divergentes podem ser complementares, o que reforça o papel do revisor, desde que ele tenha a expertise exigida pelo artigo. Vale dizer que a organização da RAE, que designa um editor científico conhecedor da área do artigo, é uma boa prática editorial, pois ele pode fazer a síntese dos pareceres e mediar o diálogo entre os revisores e o autor.

O conceito de Postura Hermenêutica se relaciona com esses aportes e limites na medida em que fornece parâmetros para que se repense a competência e a qualidade do processo de avaliação de artigos científicos pelo revisor. Espera-se, com isso, colocar o tema na agenda dos pesquisadores, promovendo a reflexão sobre o fazer cotidiano da academia. Por detrás da produtividade exigida dos cursos de pós-graduação existe uma massa de pesquisadores que estão solidariamente avaliando os artigos e aprimorandoos, mas também avaliando artigos com pressa e com qualidade duvidosa. 


\section{CONSIDERAÇÕES FINAIS}

A questão central que orientou esta investigação foi: Qual a contribuição da Hermenêutica de Gadamer para a avaliação de artigos científicos na área de Administração? Para respondê-la, essas contribuições foram subdivididas em teóricas e práticas.

\section{CONTRIBUIÇÕES TEÓRICAS}

Aquele que procura compreender (nosso revisor) está ligado à coisa transmitida (artigo) e mantém ou adquire um nexo com a tradição (acadêmica) da qual fala o artigo. Assim, um texto (o parecer) só se torna "falante" graças às perguntas (critérios de avaliação) que o revisor dirige atualmente ao artigo (GADAMER, I994a). É, sobretudo, no âmbito das recomendações e sugestões dos revisores que podemos identificar sua contribuição para além dos aspectos formais que pedem as revistas acadêmicas e onde, segundo Gadamer (1994a), o leitor-intérprete lança mão de sua tradição acadêmica, fundindo o seu horizonte (expectativas, perguntas, preconceitos) com o horizonte do texto (que também o interpela). Aqui, o conceito de fusão de horizontes, de Gadamer (1994a), se faz presente de forma original na leitura do processo de revisão por pares.

A interpretação de um texto, para Gadamer(1994b), decorrerá do encontro do eu que escreve com o eu que lê. É por isso que a tarefa da Hermenêutica não consiste em desenvolver um procedimento da compreensão, mas em iluminar as condições sob as quais acontece o compreender. A Postura Hermenêutica, defendida neste trabalho, é, portanto, mais uma atitude relativa às condições de possibilidade da compreensão e interpretação de um texto, do que de uma metodologia. Ela requer sensibilidade, honestidade intelectual e formação ampla.

Dada à subjetividade no campo da interpretação, não há como obter uma interpretação fidedigna que seja condizente com as intenções de quem escreve. Para efeito de uma análise de pareceres à luz da Postura Hermenêutica podemos dizer que os critérios do revisor devem ser uma resposta competente, aberta ao "texto que fala, interpela" (GADAMER, I994a), 
em diálogo com outras áreas afins, o que idealmente pressupõe maturidade na tarefa de avaliação de artigos científicos. Ora, como os preconceitos do revisor são, em boa parte, frutos da tradição em que ele está inserido e/ou da tradição em que foi formado, a Postura Hermenêutica propõe um encontro da particularidade subjetivista do intérprete com a particularidade objetiva da obra, numa fusão de horizontes (GADAMER, I994a, p.68-69).

Entendemos que quanto mais critérios um revisor considere - tanto globais quanto analíticos, recomendados pela revista e/ou levantados por sua expertise (do revisor) - maior é a quantidade de "perguntas" que lhe são dirigidas pelo texto e que favorecem o diálogo com ele, numa "fusão de horizontes", como pretendida por Gadamer (I994a, p.68-69). Isto significa também que se pode chegar a resultados (ou pareceres) distintos, justamente por causa desta interação ou diálogo entre texto e intérprete, ao contrário de um maior formalismo ou "unanimidade" quando falta expertise e maturidade (autoconhecimento) por parte do revisor. Tal conceito-atitude permite buscar fidelidade - não só ao que o texto é, mas também ao que o texto pode vir a ser - a despeito da interferência de inevitáveis preconceitos do seu intérprete-revisor.

A convergência entre pareceres de revisores de um mesmo artigo, portanto, só é possível em relação a dimensões objetivas ou formais do texto, não sendo possível em relação a dimensões transcendentais, uma vez que a busca de uniformidade compromete a fusão de horizontes e pressupõe uma visão positivista da avaliação. Quanto menos expertise e maturidade, mais o revisor se atém a critérios formais, o que pode favorecer mais unanimidade entre revisores.

Concorreu para a definição de Postura Hermenêutica a opção por uma abordagem que evita tanto o reducionismo funcionalista quanto o interpretativista, porque se propõe a investigar um fenômeno particularmente complexo e paradoxal. A experiência de pesquisar os instrumentos de avaliação das duas Revistas e os pareceres de seus revisores confirmou a tese de que não há objetividade e nem subjetividade absolutas no ato de compreender e interpretar um texto. $\mathrm{Na}$ tarefa acadêmica de avaliar a relevância de um artigo não é possível a objetividade pretendida por aqueles 
que defendem uma avaliação positivista, visto que as contribuições que o revisor oferece ao texto e a seu autor derivam do repertório da sua formação, aqui entendida no sentido gadameriano de tradição (GADAMER, 1994a). Nem tampouco é possível afirmar que a revisão de artigo é algo absolutamente subjetivo, fruto das idiossincrasias e preconceitos do revisor.

\section{CONTRIBUIÇÕES PRÁTICAS}

A falta de estrutura de revistas de departamento, aquelas criadas nos programas de pós-graduação, ainda que sejam revistas classificadas no Sistema Qualis, pode comprometer a qualidade da avaliação dos artigos (DINIZ, 20I2b, 20I2c).

Fragilidades na avaliação por pares pode se dar em decorrência da insuficiência e imprecisão de critérios de avaliação do artigo por parte da revista, o que pôde ser verificado na política da revista colombiana. $\mathrm{O}$ formulário de avaliação da revista deve conter tanto questões objetivas, facilmente identificadas mesmo por quem não é expert na área temática do artigo, quanto permitir ao revisor avaliar, com base no seu conhecimento, a relevância e a contribuição real e potencial do artigo.

A tarefa do revisor enquanto leitor-intérprete do texto científico requererá não só uma técnica, mas antes de tudo um tato, uma sensibilidade, uma atitude. A identificação da relevância do artigo depende da Postura Hermenêutica, que prevenirá a avaliação de subjetivismos e preconceitos nocivos. O desenvolvimento e cultivo desta competência pressupõem formação continuada e trabalho em equipe numa rede de solidariedade acadêmica (PATRUs; LIMA, 20I4). A adequada avaliação da relevância de artigos científicos na área de Administração exige uma unidade dialética entre a objetividade do texto e a subjetividade do intérprete-revisor.

Em ambas as Revistas, o editor científico está sozinho para julgar a qualidade do artigo, sem que o autor do artigo conte com o benefício da dúvida. Recomendamos vivamente que também os editores (THIRYCHERQUES, 2005), além dos tradicionais revisores, sejam incluídos na avaliação blind, para que se evite o máximo de preconceitos no processo de avaliação do artigo científico. O conhecimento da identidade e da filiação institucional 
do autor pelo editor pode comprometer a Postura Hermenêutica a ser adotada na avaliação do artigo.

O treinamento de revisores garante apenas a avaliação formal do artigo. A avaliação de sua relevância e contribuição para a Área exige formação do revisor, pois demandará dele a sua tradição. Todo o cuidado formal da revista é suficiente para refutar artigos mal escritos, mas é insuficiente para avaliar artigos relevantes para a área. O que poderia parecer uma fragilidade no processo de avaliação de artigos - a falta de consenso - é na perspectiva gadameriana, sua riqueza (GADAMER, 2005 apud BRESOLIN, 2008). Isto nos remete, mais uma vez, para a importância de formação ampla do revisor tanto no seu autoconhecimento quanto à contribuição em um cérebro coletivo (PATRUS; LIMA, 20I4). A preocupação, portanto, não pode ser em se garantir unanimidade, mas considerar o maior número possível de contribuições/olhares, suas convergências e divergências, em diálogo para o aperfeiçoamento do artigo.

A identificação da relevância do artigo científico depende também da tradição (acadêmica) do revisor, que favorece a necessária fusão de horizontes e que promoverá o aperfeiçoamento do artigo, como convém ao processo de avaliação por pares. A tradição acadêmica do revisor é fruto da sua formação, em sentido amplo. Essa formação exige não apenas o conhecimento que se chamou de expertise, como também uma Postura Hermenêutica. Trata-se, portanto, de um olhar crítico para com o texto e de uma autocrítica para com os próprios preconceitos, de modo a colocá-los a serviço da tarefa de avaliação de artigos.

Como um desdobramento, a pesquisa apontou as defesas de dissertação e de tese como momentos privilegiados para a realização da Postura Hermenêutica, apresentando-se, assim, como campo fecundo para novos estudos e pesquisas sobre a hermenêutica da atividade avaliativa feita por pares no ambiente acadêmico.

Outra implicação destas contribuições se refere ao diálogo dos autores com os revisores, numa eventual etapa de aprimoramento do artigo. Os autores, tanto quanto possível "distanciados" do texto que escreveram e imbuídos também da Postura Hermenêutica, podem se colocar diante do 
que o texto dos pareceres lhes fala, seja para acolher ou se opor, contribuindo para um diálogo fecundo que aos dois lados favorece.

A pesquisa confirmou com base no olhar hermenêutico de Gadamer e da pesquisa empírica, que o processo de avaliação de artigos exige a fusão de horizontes, ou seja, o encontro entre a tradição do leitor e o próprio texto (GADAMER, I994a). Avaliações absolutamente objetivas se limitam a critérios formais, próprios da fase de desk review do processo de avaliação de um artigo. Elas podem ser suficientes para rejeitar um artigo, mas não para avaliar a sua relevância para a área.

Por consequência, esta pesquisa contribui também para uma crítica à baixa qualidade de pareceres de artigos científicos, na medida em que, diante das condições de possibilidade da compreensão e interpretação de um texto, reconhecemos o grau de parcialidade (ou de preconceitos prejudiciais) a que todos estamos sujeitos enquanto leitores-intérpretes-revisores. Para tanto, propomos o conceito de Postura Hermenêutica, um conjunto de pressupostos e atitudes que, acreditamos, pode dar mais qualidade e segurança ao processo de avaliação de artigos científicos. Particularmente na área de Administração, cremos que o aprimoramento da revisão por pares terá reflexos positivos na avaliação de nossos Mestrados e Doutorados, já que a publicação acadêmica é uma prioridade no âmbito da avaliação de programas de pós-graduação no Brasil. 


\section{REFERÊNCIAS}

AKTOUF, O. Méthodologie des sciences socials et approche qualitative des organizations: une introduction à la démarche classique et une critique. Presses de l'Úniversité du Québec et HEC Presses, 1990.

ALCADIPANI, R. Academia e a fábrica de sardinhas. Organizações \& Sociedade, v.18, n.57, p.345-348, 2011.

\section{ASSOCIAÇÃO NACIONAL DE PÓS-GRADUAÇÃO E PESQUISA EM}

ADMINISTRAÇÃO. Boas práticas da publicação científica: um manual para autores, revisores, editores e integrantes de corpos editoriais. 2010. Disponível em: http:/ / www. anpad. org.br/diversos/boas_praticas.pdf. Acesso em: 09/07/2011.

BARDIN, L. Análise de conteúdo. Lisboa, Portugal: Edições 70, 2003.

BERTERO, C. O.; CALDAS, M. P.; WOOD JR., T. Produção científica em administração de empresas: provocações, insinuações e contribuições para um debate local. Revista de Administração Contemporânea, v.3, n.1, p.147-178, 1999.

BONFIM, V. S. Gadamer e a experiência hermenêutica. Revista CEJ, v.49, n.49, p.76-82, 2010.

BRESOLIN, K. Gadamer e a reabilitação dos preconceitos. Intuitio, v.1, n.1, p.63-81, 2008.

BRITO, E. P. Z. [Editorial]. Revista Angrad, v.10, n.2, 2009.

CALDAS, M. Paradigmas em estudos organizacionais: uma introdução à série. Revista de Administração de Empresas, v.45, n.1, p.53-57, 2005.

CRUZ, M. L. I. G. da. A avaliação na educação superior: a contribuição da CAPES para o aprimoramento dos programas de pós-graduação stricto sensu de Administração. 2009. 173 f. Tese (Doutorado em Educação e Currículo). Pontifícia Universidade Católica de São Paulo, São Paulo, Brasil, 2009.

CURY, C. R. J. Quadragésimo ano do parecer CFE nº 977/65. Revista Brasileira de Educação, n.30, p.7-20, dez. 2005.

DINIZ, E. [Editorial]. Revista de Administração de Empresas, v.52, n.4, 2012a.

DINIZ, E. [Editorial]. Revista de Administração de Empresas, v.52, n.5, 2012b.

DINIZ, E. [Editorial]. Revista de Administração de Empresas, v.52, n.6, 2012c.

DISCHINGER, B. Apresentação. In: GRONDIN, J. Introdução à hermenêutica filosófica. São Leopoldo: UNISINOS, 2003, p.9-18.

FITZPATRICK, K. Planned Obsolescence: publishing, technology, and the future of the academy. NYU Press Short: Kindle Edition, 2011.

FONSECA, C. Avaliação dos programas de pós-graduação: do ponto de vista de um nativo. Horizontes Antropológicos, v.7, n.16, p.261-275, 2011. 
FREITAS, M. H. A. Avaliação da produção científica: considerações sobre alguns critérios. Psicologia Escolar e Educacional, v.2, n.3, p.211-228, 1998.

GADAMER, H-G. Sobre el círculo de la comprensión (1959). Verdad y método II (segunda edición). Salamanca: Ediciones Sigueme, p.63-70, 1994a.

GADAMER, H-G (1994b). Texto e interpretación (1984). Verdad y método II (segunda edición). Salamanca: Ediciones Sigueme, p.319-347, 1994b.

GODOY, A. S. Introdução à pesquisa qualitativa e suas possibilidades. Revista de Administração de Empresas, v.35, n.2, p.57-63, 1995.

GRONDIN. J. Introdução à hermenêutica filosófica. São Leopoldo: Unisinos, 1999.

HAMES, I. The current state of peer review: criticisms, challenges and innovations.

Conferência apresentada no Workshop de Editoração Científica, no Encontro da Associação Brasileira de Editores Científicos, Florianópolis, SC, 2012.

HERRERO, F. J. Hermenêutica transcendental. Sintese, v.36, n.115, p.173-196, 2009.

INTERNATIONAL COMMITTEE OF MEDICAL JOURNAL EDITORS. Uniform Requirements for Manuscripts Submitted to Biomedical Journals. Disponível em: www.icmje. org. Acesso em: 12/01/2013.

JARAMILLO, I. D. T.; HINCAPIÉ, J. M. M.; PATRUS, R. Aproximación conceptual para la construccción de un modelo de orientación de la actividad científica y tecnológica em países de América Latina, como parte de uma estratégia que contribuya al desarrollo econômico de los países (documento de trabajo). IV Encontro de Ensino e Pesquisa em Administração e Contabilidade. Brasília, DF, 3-5 novembro, 2013.

KIRSCHBAUM, C.; MASCARENHAS, A. O. Nos limites da autonomia: reflexões sobre práticas de blind review e editoria de revistas científicas em administração no Brasil. Revista de Administração de Empresas-eletrônica, v.8, n.1, p. 1-21, 2009.

LEITE, N. R. P., KNIESS, C. T.; RODRIGUES, A. C. A.; MACCARI, E. A. A ética na produção, orientação, submissão, avaliação e publicação científica: quem assume a responsabilidade? Artigo apresentado no Encontro de Ensino e Pesquisa em Administração e Contabilidade, João Pessoa, PB, Brasil, 2011.

MACCARI, E. A. Contribuições à gestão dos programas de pós-graduação stricto sensu em administração no Brasil com base nos sistemas de avaliação norte americano e brasileiro. 2008. 250 f. Tese. Faculdade de Economia, Administração e Contabilidade. Doutorado em Administração. Universidade de São Paulo. São Paulo, 2008.

MACHADO, A. M. N. Políticas que impedem o que exigem: dimensões controvertidas na avaliação da pós-graduação brasileira. Universidade e Sociedade, v.39, p.137-149, 2007.

MATTOS, P. Nós e os índices - a propósito da pressão institucional por publicação. Revista de Administração de Empresas, v.48, n.2, p.144-149, 2008.

MATTOS, P. Pés de barro do texto "produtivista" na academia. Revista de Administração de Empresas, v.52, n.5, p.566-573, 2012. 
NASCIMENTO, L. F. Modelo CAPES de avaliação: quais as consequências para o triênio 2010-2012? Administração: Ensino e Pesquisa, v.4, n.11, p.579-600, 2010.

NOSELLA, P. A pesquisa em educação: um balanço da produção dos programas de pósgraduação. Revista Brasileira de Educação, v.15, n.43, p.177-183, 2010.

PATRUS, R.; DANTAS, D.; SHIGAKI, H. Produtivismo e solidariedade acadêmica: dois lados da mesma moeda? Encontro de Ensino e Pesquisa em Administração e Contabilidade, Brasília, 16p, 2013.

PATRUS, R.; LIMA, M. C. A formação de professores e de pesquisadores em Administração: contradições e alternativas. Economia \& Gestão, v.4, n.34, p.4-29, 2014.

RODRIGUES, S. B. De fábricas a lojas de conhecimento: as universidades e a desconstrução do conhecimento sem cliente. In Fleury, M.T.; de Oliveira, J.R. (Orgs.), Gestão estratégica do conhecimento: integrando aprendizagem, conhecimento e competências. São Paulo: Atlas, 2001, p.86-117.

ROESCH, S. M. A. Quem responde pelo desempenho limitado da produção científica em Administração no Brasil? Organizações \& Sociedade, v.10, n.28, p.165-167, 2003.

SGUISSARDI, V. Produtivismo acadêmico. In: Oliveira, D. A.; Duarte, A..; Vieira, L.. (Orgs.). Dicionário de Trabalho, Profissão e Condição Docente. Belo Horizonte, MG: Faculdade de Educação/UFMG, 2010.

SHIGAKI, H. B. Revisão por pares em um contexto de produtivismo acadêmico sob a ótica dos avaliadores de artigos de periódicos científicos na área de Administração. 2014. 123 f. Dissertação. Mestrado em Administração. Programa de pós-graduação em Administração. Pontifícia universidade Católica de Minas Gerais. Belo Horizonte, 2014.

SILVA, L. P. F. Da "fusão de horizontes" ao "conflito de interpretações": a Hermenêutica entre H.-G. Gadamer e P. Ricoeur. Revista Filosófica de Coimbra, v.1, n.1, p.127-153, 1992.

SMITH, R. Peer review: a flawed process at the heart of science and journals. Journal of the Royal Society of Medicine, v.99, n.1, p.178-182, 2006.

STUMPF, I. Avaliação pelos pares nas revistas de comunicação: visão dos editores, autores e avaliadores. Perspectivas em Ciência da Informação, v.13, n.1, p.18-32, 2008.

THIRY-CHERQUES, H. R. Comentando: 'A face oculta do parecerista: discussões éticas sobre o processo de avaliação de mérito de trabalhos científicos'. Organizações \& Sociedade, v.12, n.32, p.181-182, 2005. 


\section{DADOS DOS AUTORES}

DOUGLAS CABRAL DANTAS ${ }^{\star}$ douglas.dantas@yahoo.com.br Doutor em Administração pela PUC Minas

Instituição de vinculação: Pontifícia Universidade Católica de Minas Gerais Belo Horizonte/MG - Brasil

Áreas de interesse em pesquisa: Ensino e Pesquisa em Administração.

*Avenida Itaú, 525 Dom Cabral 30535-012 Belo Horizonte/MG

ROBERTO PATRUS robertopatrus@pucminas.br Doutor em Filosofia pela Universidade Complutense de Madrid

Instituição de vinculação: Pontifícia Universidade Católica de Minas Gerais Belo Horizonte/MG - Brasil

Áreas de interesse em pesquisa: Ensino e Pesquisa em Administração; Ética nos negócios. 